\title{
Practice of "Internet Thinking + Dichotomy Classroom" Teaching Mode in New Media Advertising Teaching
}

\author{
Zheng Lingling \\ School of Humanities, Xi'an University of Arts and Science, Xi'an, Shaanxi, China, 710065
}

Keywords: Internet Thinking; Dichotomy classroom; Advertising Teaching

Abstract: Internet thinking as an innovative thinking, focusing on user experience, its Internet concept and spirit provides new ideas for the reform and development of education. The dichotomy course is a new interactive learning mode. It integrates the user, platform and social thinking of Internet thinking into the dichotomy classroom teaching mode, and explores the internal optimization and innovation in the practice of new media advertising courses.

\section{Introduction}

The Internet is constantly refactoring people's production and life styles. What is behind it is a new perspective on development concepts and cognitive reorganization, namely Internet thinking. In August 2014, General Secretary Xi Jinping delivered an important speech during the fourth meeting of the leading group for the comprehensive deepening reform of the central government, stressing that "the law of emerging media should be followed and the Internet thinking should be strengthened". After that, the concept of "Internet thinking" was rapidly popularized. Its main features include user first, platform openness, cross-border integration, vertical in-depth, experience as the core, big data application, etc. It is characterized by the pursuit of user perspective and iterative innovation. The essence of Internet + education is to use the Internet thinking to stimulate the vitality of higher education, and deeply integrate it into all aspects of higher education as an innovative element. Therefore, the integration and reorganization of Internet thinking and higher education will inevitably have innovative value and practical significance.

\section{The Necessity of Deep Integration of Internet Thinking and Advertising Teaching}

The innovation and reconstruction of teaching mode is not a simple multimedia teaching, not a distance education or online education, but a subversive reconstruction from the inside to outside. First of all, it is necessary to innovate the teaching thinking of advertising. As advertising teaching is inseparable from changes in the market economy, we should actively integrate the Internet thinking mode, subverting solidified thinking from the inside to outside. Besides, we should realize the goal of advertising teaching reform with multi-dimensional thinking, and realize the innovation of teaching thinking to promote the essence of reform. At the same time, we should be guided by the network thinking mode, abandon the single and biased traditional teaching mode, focus on the integration of basic knowledge and practical ability training of advertising teaching, and promote the integration of disciplines and dilute the boundaries. In the final analysis, it is to carry out 
all-round and deep thinking innovation, and integrate and share social resources to promote the continuous optimization of advertising education mode. Second, it is necessary for the transformation of advertising teaching technology. The cross-disciplinary of advertising science needs to constantly update teaching technology, and "Internet + " is to carry out all-round transformation through the integration of resources and technology, and realize the transformation of the core nature of educational technology. Innovate in the deep structure of teaching methods and iteratively optimize in practical functions. The concepts of "content design, technology development, resource utilization, ecological management and comprehensive evaluation" will be fully developed to achieve an in-depth integration of Internet thinking and teaching to form an innovative system to better serve advertising teaching.

\section{Dichotomy Classroom and Internet Thinking}

\subsection{Teaching Concept of Dichotomy Classroom}

The dichotomy classroom is a new teaching mode based on interactive learning proposed by Professor Zhang Xuexin from the Department of Psychology of Fudan University. The dichotomy classroom transforms the traditional classroom into a platform for communication between teachers and students. It is clearly divided into three processes in time, namely, teaching, internalization and absorption, and discussion. The first stage of teaching is that teachers explain difficult knowledge structure and guide students to think. The second stage of internalization and absorption is that students learn and think more deeply about their knowledge according to the learning situation of the classroom, and internalize it into their own experience. The third stage of discussion is that students discuss and share about the new problems in learning, thus further deepening the understanding and internalization of the knowledge they have learned. It can be seen that the dichotomy classroom first highlights the student-oriented instructional design, and make teacher's role orientation and timely conversion in the teaching process, so that students can truly participate in the classroom teaching and promote the development of their learning ability and innovative thinking. Second, the dichotomy classroom highlights the core literacy of 4C goals, that is, (Collaboration, Communication, Creativity, and Critical Thinking). Through teaching, it can promote students to independently think, discover problems, discuss and share, and provide an highly effective plan for cultivating core literacy. Third, dichotomy classroom increases the interpersonal interaction between teachers and students, and effectively cultivates the social abilities of students' emotional intelligence. In the dichotomy classroom, cooperation and communication are included in the regular learning process, and students have a lot of time to listen to each other and express themselves.

\subsection{New Requirements for Advertising Teaching in the Dichotomy Classroom}

First, innovative teaching thinking is needed for advertising teachers. From the perspective of students' needs, they ask questions, think about and solve problems, update teaching concepts, and go from standardization to personalized teaching of "teaching students according to their aptitude". Combining the needs and interests of different content of students, teachers should design teaching points with new media advertising environment and knowledge framework, and integrate the teaching of single courses in multidisciplinary fields. At the same time, teachers need to have strong flexibility to guide. The teaching of dichotomy is mainly based on students. It emphasizes students' initiative and ability to explore and cooperate, promotes the development of creative thinking, makes teaching more flexible, and brings greater challenges to teachers' teaching and guiding ability. New media advertising has more cutting-edge dynamic knowledge, so that teachers need to have 
strong new media factor analysis ability and thinking insight to better guide students to think. Teaching methods should be diversified to suit different levels of students with different needs. Second, it is necessary for students to develop active cognitive thinking skills. From "passive" to "active", cognitive changes are needed. From the independent thinking of the internalization and absorption of the dichotomy to the group collaboration discussion, it is a process of active exploration. The new media advertising course needs to think about problems with continuous development and change thinking, and it fully reflects the creative and critical initiative in the aspects of group cooperation, communication, and questioning and answering. At the same time, dichotomy classroom innovate the learning style of students and strengthen the extension of the curriculum knowledge points through the open platform of resource sharing and exchange.

\subsection{The Enlightenment of Internet Thinking on the Dichotomy Classroom}

As a kind of concept system that emphasizes user and value orientation and mode innovation, Internet thinking has profoundly affected many industries and fields with its spiritual core and concept extension. The dichotomy classroom contains many features, such as the subversive innovation concept of teaching structure, the values of equality and mutual help between teachers and students, the intensive sharing of teaching platforms and materials, and the interaction between teachers and students. All of them are in line with the core connotations and the external forms of Internet thinking. It is not only the inevitable choice for the reform and development of teaching, but also the proper meaning of the innovation of teaching mode, which uses Internet thinking to examine and respond to the concept and form of education reform and development, and to guide the path of dichotomy classroom teaching mode.

First, the user's thinking is involved in the positioning and development of the dichotomy design. Advocating the student-oriented dichotomy classroom teaching mode, it is necessary to highlight the value concept of student-centered in mode design and application practice. At this point, it coincides with the idea of user thinking as the core thinking in Internet thinking. With the user-centered thinking of Internet thinking, in the development and design of the "teaching products", that is, the learning content and materials of the new media advertising courses, the "teaching users", that is, students' experiences and needs, are widely integrated. On the one hand, it can closely integrate the actual needs of students and stimulate students' enthusiasm and initiative to a greater extent. On the other hand, students can deepen their understanding of knowledge content and further improve their operational skills and practical application ability in the design of participating learning programs. Second, platform thinking builds a space for sharing resources and promotes the cultivation of students' core literacy. Through the "Internet +" platform, an advertising course resource library is built, and teaching is a resource sharing that integrates multidisciplinary backgrounds. Teachers use social and professional resources to optimize the structure and content of the curriculum, and a large number of high-quality resources are poured into the learning activities to open up students' horizons and improve their quality of learning. Third, socialized social thinking promotes the extension of the network communication and teaching content of the dichotomy classroom, and accelerates the multi-disciplinary integration of the subject. Dichotomy teaching encourages students to view the learning process with creative and critical thinking. Socialized social thinking can open up multiple network associations, allowing a single problem to be single-minded and multi-integrated, and the learning process is more interactive and creative. 


\section{Practice of Internet Thinking + Dichotomy Classroom in New Media Advertising Teaching}

\subsection{Pre-class Teaching Research and Knowledge Frame Design Based on User Thinking}

User thinking refers that we must consider problems with "user-centered"mindset in all aspects of the value chain. Before the start of the new media advertising course, teachers should follow the student-centered teaching philosophy, and take the students' characteristics, abilities, and needs as the starting point and goal of teaching activities. According to the learning needs of students, the teaching plan and the core knowledge system framework are formulated to motivate students to learn. This course focuses on the new media environment and is closely related to the dynamics of social network hotspots. The practice of many cases comes from the reconstruction and understanding of the new media knowledge system. First, teachers should guide students to summarize new media cases and events that are relevant to each course's knowledge points. Then let them look for internal connections, ask questions and opinions. Besides, teachers should comply with the student group's concerns and interests to write teaching ideas and plans, and organize materials to develop the course explanation core and case analysis. For example, the analysis of the new media network marketing environment and online marketing cases, such as double eleven, are activities that are frequently contacted or participated by the student information environment, and have a certain understanding of their advertising marketing cognition. According to students' existing situation and demand feedback, targeted design teaching guidance, which can explore deep-seated problems to guide students, creatively explore multi-dimensional perspectives, and activate teaching content. Students are both users and participants and designers of teaching activities. In the self-learning stage before class, the team members need to actively respond to other students' questions and suggestions through WeChat group or message board, and continue to lead the learning activities.

\subsection{In-class Teaching, Internalization and Absorption, and Discussion Based on Platform Thinking}

Platform thinking is to connect the channels with various needs through the establishment of the platform, solve the problems by exchanging resources, and closely link through sharing information. Platformization is more adaptive to ad media updates and multi-dimensional thinking under changing and iterative. Introducing multiple information resources into the dichotomy classroom, the three stages will be the combination of various authoritative forces. After professionally teaching and explaining advertising cases and network hot events, the teaching will be more vertical and in-depth. We should try our best to avoid teachers' teaching bias, disconnection and rigidity due to insufficient knowledge structure and information mastery. For the new media advertising course, teachers should link to various advertising professional network resource library, joint production and education to integrate enterprise business media operation cases, and activate the teaching platform. Students use different online and offline resources in different class groups to ask questions to solve problems and share communication to carry out in-depth cooperative learning.

\subsection{After-class Network Communication and Homework Practice Sharing Based on Social Thinking}

Social thinking is a network development thinking mode of Internet socialization. Introducing this kind of thinking into the teaching of new media advertisements, we can improve the communication platform of the dichotomy teaching, explore the development relationship between single case and knowledge point in the form of multi-network communication, and find a new 
cognitive point in depth. Students communicate with each other through the cyberspace of the new media advertising program. Teachers publish assignments and related materials through the cyberspace. The sharing and communication between students and teachers has become a network structure, and some front-end questions and answers have become more diverse and more valuable. Homework practice is an important part of the new media advertising program. Students use the online new media, such as WeChat, Weibo operations, social communication and interaction to enhance practical operation capabilities. Students should group and implement new media marketing and promotion practices for campus activities, select new media operations for campus cultural and creative products, and summarize operational experience. Finally, they can communicate on the curriculum platform to enhance creativity, communication and collaboration. New media advertising practice cases verify the effective dissemination through the socialized dissemination of various platforms. And then discuss and explore with each other to complete practical training. After-class learning sharing has become a carrier of social interaction. Let learning integrate with society, which can greatly stimulate students' investment in learning.

\section{Conclusion}

The dichotomy classroom teaching that integrates Internet thinking is a kind of innovation of ideas. It takes the Internet as the infrastructure and innovation factor to innovate the organizational, service and teaching mode of education, and then builds a new teaching ecosystem in the digital age. This system has changed the traditional "teacher-centered" teaching mode, and transforms teaching mode into "learner-centered" to provide students with a full, personalized and continuous learning service.

\section{Acknowledgement}

This thesis is the result of "New Media Advertising", the key course project of 2018 teaching reform of Xi'an University of Arts and Sciences. (Item No.: KGB201807)

\section{References}

[1] Chen Li, Lin Shiyuan and Zheng Qinhua. Opportunities and Challenges of Distance Education in China in the Age of "Internet +" [J]. Modern Distance Education Research, 2016 (1): 3-10.

[2] Zhang Yan. Analysis of the Concept and Mode of "Internet + Education" [J]. China Higher Education Research, 2016 (2): 71.

[3] Xie Youru, Wu Lihong, Qiu Yi, Zhang Huiyan and Li Wei. Innovative Teaching Practice Research with Internet Thinking: Curriculum Perspective [J]. China Audio-visual Education, 2017 (10): 1-7.

[4] Huang Jian. Leading Chinese "Internet +" Education Strategy with Internet Thinking [J]. China Audio-visual Education, 2017, (1): 99-104.

[5] Dang Jianning and Yang Xiaohong. The Flipping Classroom Teaching Mode under Internet Thinking: Values and Design Innovation [J]. Audio-visual Education Research, 2017, 38 (11): 108-114.

[6] Qiu Aimei. The Idea and Practice of the Teaching Mode of "Dichotomy Classroom" [J]. Journal of Guangdong University of Foreign Studies, 2016, 27 (03): 140-144.

[7] Zhang Peng. Exploration of the Mixed Teaching Mode of New Media Advertising Course [J]. News World, 2017 (12): $94-96$.

[8] Deng Xinqiang and You Chunxia. Re-recognition of the "Dichotomy Classroom" Teaching Mode in Colleges and Universities [J]. Knowing and doing, 2017 (10): 134-139.

[9] Chen Peiai and Chen Hongbo. Research on the Relationship between the Core Forces of Advertising Industry Development in the New Media Era-Analysis Based on the Technology, Media and Creativity [J]. Journal of Yulin Teachers College, 2018, 39 (01): 2-8.

[10] Wang Erfu. The Reform of the Teaching Mode of College Dichotomy Classroom under the Network Environment [J]. Journal of Higher Normal Science, 2016, 36 (05): 89-91+97. 